\title{
Expression of Notch-1 and alteration of the E-cadherin/ $\beta$-catenin cell adhesion complex are observed in primary cutaneous neuroendocrine carcinoma (Merkel cell carcinoma)
}

John Panelos ${ }^{1}$, Anna Batistatou ${ }^{2}$, Milena Paglierani ${ }^{1}$, Aikaterini Zioga ${ }^{2}$, Vincenza Maio ${ }^{1}$, Raffaella Santi ${ }^{1}$, Nicola Pimpinelli ${ }^{3}$, Vincenzo De Giorgi ${ }^{3}$, Marco Santucci ${ }^{1}$ and Daniela Massi ${ }^{1}$

${ }^{1}$ Department of Human Pathology and Oncology, University of Florence, Florence, Italy; ${ }^{2}$ Department of Pathology, University of Ioannina Medical School, Ioannina, Greece and ${ }^{3}$ Department of Dermatological Sciences, University of Florence, Florence, Italy

\begin{abstract}
Increasing evidence indicates that Notch signaling contributes to physiological processes, including development and differentiation, as well as tumorigenesis, either as a tumor promoter or suppressor, depending on cellular context, expression levels and cross talk with other signaling systems. Recent studies reported absent or minimal Notch-1 expression in neuroendocrine tumors of the lung and gastrointestinal tract, suggesting a tumor-suppressor function of Notch-1. Merkel cell carcinoma is a rare and highly aggressive primary cutaneous neuroendocrine carcinoma. Because no information is available on Notch-1 expression in this tumor, we have investigated a series of 31 Merkel cell carcinoma for Notch-1 immunoreactivity. Immunoreactivities for E-cadherin and $\beta$-catenin were also analyzed. All but 1 Merkel cell carcinoma (30 of 31) retained cytoplasmic and membrane Notch-1 expression in more than $50 \%$ of cells. $\beta$-Catenin displayed a prevalent membrane-associated staining in 30 of 31 cases, and 22 cases showed more than $50 \%$ of immunoreactive cells whereas nuclear $\beta$-catenin was seen only in 2 of 31 cases. E-cadherin membranous expression was remarkably low, as only 1 of 26 cases was found positive in more than $50 \%$ of cells. In contrast with neuroendocrine tumors in other tissues, evident Notch-1 expression was found in Merkel cell carcinoma. This finding does not support a tumor-suppressor function of Notch-1 in Merkel cell carcinoma. Downregulation of E-cadherin and diffuse membranous $\beta$-catenin expression suggest a dysregulation of the E-cadherin/ $\beta$-catenin complex in Merkel cell carcinoma. This may contribute to local invasion and distant metastasis. Modern Pathology (2009) 22, 959-968; doi:10.1038/modpathol.2009.55; published online 24 April 2009
\end{abstract}

Keywords: notch-1; $\beta$-catenin; E-cadherin; Merkel cell carcinoma; neuroendocrine

Notch signaling controls a variety of processes, involving cell fate specification, differentiation, proliferation and survival. ${ }^{1}$ Its pathway includes a family of transmembrane receptors and their ligands, negative and positive modifiers and transcription factors. To date, four mammalian transmembrane receptors (Notch 1-4) and five transmembrane ligands (Jagged 1,2 and Delta 1, 3

Correspondence: Professor D Massi, MD, Dipartimento di Patologia Umana ed Oncologia, Università degli Studi di Firenze, Viale G.B. Morgagni 85, I-50134 Firenze, Italia.

E-mail: Daniela.massi@unifi.it

Received 6 November 2008; revised and accepted 2 February 2009; published online 24 April 2009 and 4) have been identified. ${ }^{2}$ The Notch signaling is initiated by receptor-ligand interaction between neighboring cells, which renders the Notch receptor susceptible to a first proteolytic cleavage by TACE (TNF- $\alpha$-converting enzyme) and subsequently, to a second intramembranous cleavage by the $\gamma$-secretase. The process results in the release of the Notch intracellular domain from the plasma membrane, which may translocate to the nucleus. Once there, it associates with the DNA-binding transcription factor, CLS (acronym for CBF1, LAG-1 and Su(H)). The binding or the formation of the complex results in the activation of the basic helix-loop-helix (bHLH) transcription factor Hes-1, thus regulating downstream target genes. ${ }^{3}$ 
In addition to a series of physiological processes, increasing evidence suggests the involvement of the Notch signaling in tumorigenesis, as the Notch pathway regulates cell proliferation, migration and apoptosis. Notch may act either as a tumor promoter or a tumor suppressor, depending on the cell type and tissue context, level of expression and potential contemporary cross talk with other signaling systems. ${ }^{4}$ Recent studies demonstrated that Notch-1 signaling is minimal or absent in carcinoids, medullary thyroid cancer and small-cell lung cancer, supporting the hypothesis of a tumorsuppressor function of Notch-1 in neuroendocrine tumors. ${ }^{5-8}$ Finally, in vitro experiments have shown that exogenous activation of Notch-1 signaling results in tumor suppression and in a significant reduction in neuroendocrine markers such as chromogranin A, serotonin and calcitonin. ${ }^{8}$

Primary neuroendocrine carcinoma of the skin or Merkel cell carcinoma is a rare and often aggressive malignant primary cutaneous cancer. ${ }^{9}$ Approximately $50-80 \%$ of cases have a regional lymph node involvement at presentation and there is a high risk of distant metastases (25-40\%) associated to significant mortality, with $25-30 \%$ of patients dying within 3 years from diagnosis. ${ }^{10,11}$ Poor knowledge of the molecular mechanisms of neoplastic transformation and difficulties in the precise classification and appropriate management are specific features of Merkel cell carcinoma. To date, none of the known tumor suppressors or oncogenes has been conclusively associated to the development of Merkel cell carcinoma and particularly none is known about the expression of a major regulator of tumorigenesis, as the Notch signaling, in Merkel cell carcinoma.

Notch-1 can inhibit $\beta$-catenin-mediated signaling, when it functions as a tumor-suppressor gene in keratinocytes and skin carcinomas, ${ }^{12}$ whereas in cutaneous melanoma $\beta$-catenin mediates the oncogenic function of the Notch pathway. ${ }^{13}$ These data suggest that differential functions for Notch signaling in skin tumors are closely related to $\beta$-catenin. $\beta$-Catenin is a multifunctional protein that controls a number of cellular activities, both at the membrane and the nuclear level. As a membrane protein, $\beta$-catenin bridges between the cytoskeleton and cadherins thus regulating $\mathrm{E}$ - or N-cadherinmediated cell adhesion, whereas in the nucleus $\beta$-catenin functions as a downstream signaling molecule of the Wnt signaling. It has been recently reported that Notch activation, through the induction of Slug, a Snail family member, represses E-cadherin promoting tumor growth and metastasis. ${ }^{14}$

The aim of the current study was to identify by immunohistochemistry Notch-1 expression in a series of 31 primary and metastatic Merkel cell carcinoma. Expressions of $\beta$-catenin and E-cadherin were also analyzed and all these immunoreactivities were compared to those found in skin metastases from neuroendocrine tumors as well as cutaneous melanoma with neuroendocrine features.

\section{Materials and methods}

\section{Specimen Selection}

The study series included human tissue samples retrieved from the archive of the Department of Human Pathology and Oncology, University of Florence. The series was composed of 31 cases of Merkel cell carcinoma from 30 patients. Of these patients, 10 were men and 20 women, and all ranged in age from 42 to 92 years (mean 76.6 years, median 79 years). The tumors were located mainly on the lower extremities (13 cases) and the head and neck region (12 cases) whereas upper extremities and trunk were involved in 5 and 1 case, respectively. Follow-up of patients ranged from 2 to 323 months (mean 60.6 months, median 37 months). Patients' data, including age, sex, anatomic site and followup, are reported in Table 1.

In addition, three cases of lung neuroendocrine tumors metastatic to the skin (two lung carcinoids, one small-cell neuroendocrine lung carcinoma) as well as one case of cutaneous melanoma with neuroendocrine differentiation were selected for the current investigation. Carcinoids were observed in two male patients of 60 and 61 years old and the cutaneous metastases were both located on the back. Small-cell neuroendocrine lung carcinoma was seen in a 73-year-old man and the skin metastasis was located on the forehead. Cutaneous melanoma with neuroendocrine differentiation was diagnosed on a shoulder of a 51-year-old man.

\section{Immunohistochemistry}

Specimens obtained by surgical resection were fixed in $10 \%$ buffered formalin and paraffin embedded. For immunohistochemical analysis a representative $4-\mu \mathrm{m}$ section for each lesion was selected. All sections for Notch-1 evaluation were deparaffinized in Bio-Clear (Bio-Optica, Mi, Italy) and hydrated using graded ethanol before to be submitted for antigen retrieval. Briefly, antigen retrieval was performed by microwave pretreatment (Microwave MicroMED T/T Mega; Milestone, Bergamo, Italy) in EDTA $1 \mathrm{mM}(\mathrm{pH}$ 8.0) for $30 \mathrm{~min}$; endogenous peroxidase activity was blocked by immersing slides in distilled water, containing $3.0 \%$ hydrogen peroxide for $20 \mathrm{~min}$. Nonspecific antigen sites were blocked with normal horse serum (UltraVision; LabVision, Fremont, CA, USA), then the sections were incubated with goat anti-human Notch-1 antibody (sc-6014) (Santa Cruz Biotechnology Inc., Santa Cruz, CA, USA) at 1:30 dilution for $1 \mathrm{~h}$. Staining was achieved using appropriate biotinconjugated anti-goat secondary antibody (IgG; Biomedicals, Verona, Italy) and a biotinylated goat anti-rabbit (UltraVision), followed by streptavidinperoxidase (UltraVision). Bound antibody was visualized using 3,3'-diaminobenzidine (Peroxidase/ DAB; Dako, Glostrup, Denmark) as chromogen. 
Table 1 Clinicopathological features of 31 primary cutaneous neuroendocrine or Merkel cell carcinomas

\begin{tabular}{|c|c|c|c|c|c|c|c|}
\hline No. & Merkel cell carcinoma & Age & Sex & Site & Status & DFI (months) & Follow-up (months) \\
\hline 1 & Primary & 54 & $\mathrm{~F}$ & Back & NED & - & 323 \\
\hline 2 & Primary & 91 & M & Neck & DOD & 4 & 5 \\
\hline 3 & Primary & 65 & $\mathrm{~F}$ & Leg & NED & - & 214 \\
\hline 4 & Primary & 84 & M & Leg & DOD & 3 & 16 \\
\hline 5 & Primary & 91 & $\mathrm{~F}$ & Cheek & DOD & 3 & 22 \\
\hline 6 & Primary & 81 & M & Leg & NED & - & 138 \\
\hline 7 & Primary & 68 & M & Front & DOD & 2 & 10 \\
\hline 8 & Primary & 81 & M & Leg & NED & - & 94 \\
\hline 9 & Primary & 57 & $\mathrm{~F}$ & Thigh & DOD & 2 & 4 \\
\hline 10 & Primary & 85 & $\mathrm{~F}$ & Thigh & DOD & 4 & 24 \\
\hline 11 & Primary & 80 & $\mathrm{~F}$ & Cheek & NED & - & 90 \\
\hline 12 & Metastatic & 78 & $\mathrm{~F}$ & Leg & DOD & 16 & 49 \\
\hline 13 & Primary & 89 & $\mathrm{~F}$ & Knee & DOD & 6 & 10 \\
\hline 14 & Primary & 73 & $\mathrm{~F}$ & Cheek & NED & - & 87 \\
\hline 15 & Primary & 78 & $\mathrm{~F}$ & Cheek & NED & - & 56 \\
\hline 16 & Primary & 89 & $\mathrm{~F}$ & Front & NED & - & 24 \\
\hline 17 & Primary & 87 & $\mathrm{~F}$ & Lip & DOC & - & 2 \\
\hline 18 & Primary & 67 & $\mathrm{~F}$ & Knee & NED & - & 80 \\
\hline 19 & Primary & 78 & M & Thigh & NED & - & 79 \\
\hline 20 & Primary & 82 & $\mathrm{~F}$ & Arm & LOST & - & - \\
\hline 21 & Primary & 92 & $\mathrm{~F}$ & Leg & LOST & - & - \\
\hline 22 & Primary & 85 & $\mathrm{M}$ & Thigh & DOD & 6 & 9 \\
\hline 23 & Primary & 79 & $\mathrm{~F}$ & Leg & NED & - & 35 \\
\hline 24 & Primary & 80 & $\mathrm{~F}$ & Forearm & LOST & - & - \\
\hline 25 & Primary $^{a}$ & 74 & M & Eyebrow & AWD & 3 & 54 \\
\hline 26 & Metastatic $^{\mathrm{a}}$ & 75 & $\mathrm{M}$ & Neck & AWD & 3 & 54 \\
\hline 27 & Primary & 86 & $\mathrm{~F}$ & Eyelid & LOST & - & - \\
\hline 28 & Primary & 42 & $\mathrm{M}$ & Arm & NED & - & 46 \\
\hline 29 & Primary & 77 & $\mathrm{~F}$ & Cheek & NED & - & 39 \\
\hline 30 & Primary & 76 & $\mathrm{~F}$ & Forearm & NED & - & 35 \\
\hline 31 & Primary & 63 & $\mathrm{M}$ & Hand & NED & - & 31 \\
\hline
\end{tabular}

M: male; F: female; NED: no evidence of disease; AWD: alive with disease; DOD: dead of disease; DOC: dead of other causes; DFI: disease-free interval.

${ }^{a}$ Primary and metastatic Merkel cell carcinomas belong to the same patient.

Table 2 List of antibodies used for immunohistochemistry

\begin{tabular}{|c|c|c|c|}
\hline Antibody & Source & Dilution & Cellular compartment \\
\hline Notch-1 (goat, polyclonal) & Santa Cruz Biotechnology Inc. & $1: 30$ & Cytoplasmic, membrane \\
\hline E-cadherin (mouse monoclonal, clone ECH-6) & Cell Marque Corporation & Prediluted & Cytoplasmic, membrane \\
\hline$\beta$-Catenin (mouse monoclonal, clone 14) & Cell Marque Corporation & Prediluted & Nuclear \\
\hline
\end{tabular}

Nuclei were slightly counterstained with Mayer's hematoxylin. Negative controls were performed by substituting the primary antibody with a nonimmune serum.

Immunohistochemical analysis for E-cadherin and $\beta$-catenin was performed on formalin-fixed, paraffin-embedded tissue sections placed on electrostatic slides and dried for $1 \mathrm{~h}$ at $60^{\circ} \mathrm{C}$. The slides were next placed on BenchMark ${ }^{\mathbb{R}}$ XT automated autostainer (Ventana Medical Systems Inc., Tucson, AZ, USA), where they were freed of paraffin and subjected to heat-induced Ventana CC1 epitope retrieval solution. Two Ventana dispenser containing prediluted monoclonal antibodies anti-E-cadherin, clone ECH-6 (Cell Marque Corporation, Rocklin, CA, USA) and anti- $\beta$-catenin, clone 14 (Cell Marque Corporation) were applied to the paraffin sections for $32 \mathrm{~min}$ each. The presence of the antigen was visualized using as revelation system the iVIEW DAB Detection Kit (Ventana Medical Systems Inc.) observing suggested protocol. After the staining run was complete, the slides were removed from the autostainer, counterstained with hematoxylin, dehydrated and mounted with permanent mounting medium (Table 2).

Substituting primary antibody with equal dilution of a nonimmune serum performed negative controls. The positive controls were lung adenocarcinoma sections for E-cadherin detection and breast fibromatosis sections for $\beta$-catenin. Control sections were treated at the same time of sample sections.

Immunostained sections were independently assessed by two observers. The results were expressed according to semiquantitative criteria as follows: 
0 , negative staining; $1+, 1-20 \%$ of positive cells; $2+, 21-50 \%$ of positive cells and $3+$, more than $50 \%$ of positive cells. The staining intensity was scored on a scale as faint, moderate or strong.

\section{Statistical Analysis}

Statistical analysis was performed using the SPSS statistical software, release 12.0 (SPSS Inc., Chicago, IL, USA). Association between different variables was assayed by the two-tailed Fisher's exact test. Continuous variables were compared using the MannWhitney $U$-test or Kruskal-Wallis $H$-test. A $P$-value $<0.05$ was considered statistically significant.

\section{Results}

The results of the immunohistochemical investigation are reported in Table 3. Notch-1 immunohistochemical expression was mostly confined to the cell cytoplasm, with peripheral membrane and occasional nuclear pattern. In normal skin, Notch-1 was strongly and diffusely expressed in suprabasal epidermal keratinocytes, with only faint and focal staining in the granular layer and stratum corneum.

Table 3 Distribution of Notch-1, E-cadherin and $\beta$-catenin expression in Merkel cell carcinoma

\begin{tabular}{|c|c|c|c|c|}
\hline No. & Merkel cell carcinoma & Notch-1 & E-cadherin & $\beta$-Catenin \\
\hline 1 & Primary & $3+(\mathrm{c}-\mathrm{m})$ & $1+(\mathrm{m})$ & $3+(\mathrm{m})$ \\
\hline 2 & Primary & $3+(\mathrm{c}-\mathrm{m})$ & 0 & $3+(\mathrm{m})$ \\
\hline 3 & Primary & $3+(\mathrm{c}-\mathrm{m})$ & $1+(\mathrm{m}-\mathrm{c})$ & $3+(\mathrm{m})$ \\
\hline 4 & Primary & $2+(\mathrm{c}-\mathrm{m})$ & $1+(\mathrm{m}-\mathrm{c})$ & $3+(\mathrm{m})$ \\
\hline 5 & Primary & $3+(\mathrm{c}-\mathrm{m})$ & $1+(\mathrm{m})$ & $3+(\mathrm{m})$ \\
\hline 6 & Primary & $3+(\mathrm{c}-\mathrm{m})$ & 0 & $2+(\mathrm{m})$ \\
\hline 7 & Primary & $3+(\mathrm{c})$ & $\mathrm{NE}$ & $1+(\mathrm{m})$ \\
\hline 8 & Primary & $3+(\mathrm{c}-\mathrm{m})$ & 0 & $1+(\mathrm{m})$ \\
\hline 9 & Primary & $3+(\mathrm{c}-\mathrm{m})$ & $1+(\mathrm{m}-\mathrm{c})$ & $2+(\mathrm{m})$ \\
\hline 10 & Primary & $3+(\mathrm{c})$ & $1+(m-n)$ & 0 \\
\hline 11 & Primary & $3+(\mathrm{c}-\mathrm{m})$ & 0 & $3+(\mathrm{m})$ \\
\hline 12 & Metastatic & $3+(\mathrm{c}-\mathrm{m})$ & $\mathrm{NE}$ & $3+(\mathrm{m})$ \\
\hline 13 & Primary & $3+(\mathrm{c})$ & $\mathrm{NE}$ & $1+(m-n)$ \\
\hline 14 & Primary & $3+(\mathrm{c}-\mathrm{m})$ & 0 & $3+(\mathrm{m})$ \\
\hline 15 & Primary & $3+(\mathrm{c}-\mathrm{m})$ & $\mathrm{NE}$ & $3+(\mathrm{m})$ \\
\hline 16 & Primary & $3+(\mathrm{c}-\mathrm{m})$ & $\mathrm{NE}$ & $3+(\mathrm{m})$ \\
\hline 17 & Primary & $3+(\mathrm{c}-\mathrm{m})$ & $1+(\mathrm{m}-\mathrm{c})$ & $3+(\mathrm{m})$ \\
\hline 18 & Primary & $3+(\mathrm{c}-\mathrm{m})$ & $3+(\mathrm{m})$ & $3+(\mathrm{m})$ \\
\hline 19 & Primary & $3+(\mathrm{c})$ & 0 & $3+(\mathrm{m})$ \\
\hline 20 & Primary & $3+(\mathrm{c}-\mathrm{m})$ & 0 & $3+(\mathrm{m})$ \\
\hline 21 & Primary & $3+(\mathrm{c}-\mathrm{m})$ & $1+(\mathrm{m})$ & $2+(\mathrm{m})$ \\
\hline 22 & Primary & $3+(\mathrm{c}-\mathrm{m})$ & $1+(\mathrm{m}-\mathrm{c})$ & $3+(\mathrm{m})$ \\
\hline 23 & Primary & $3+(\mathrm{c}-\mathrm{m})$ & $1+(\mathrm{m})$ & $3+(\mathrm{m})$ \\
\hline 24 & Primary & $3+(\mathrm{c}-\mathrm{m})$ & $1+$ & $3+(\mathrm{m})$ \\
\hline 25 & Primary & $3+(\mathrm{c}-\mathrm{m})$ & $1+(\mathrm{c})$ & $3+(\mathrm{m})$ \\
\hline 26 & Metastatic & $3+(\mathrm{c}-\mathrm{m})$ & 0 & $3+(\mathrm{m})$ \\
\hline 27 & Primary & $3+(\mathrm{c}-\mathrm{m})$ & $1+(\mathrm{n})$ & $2+(\mathrm{m})$ \\
\hline 28 & Primary & $3+(\mathrm{c}-\mathrm{m})$ & 0 & $3+(n-m)$ \\
\hline 29 & Primary & $3+(\mathrm{c}-\mathrm{m})$ & 0 & $2+(\mathrm{m})$ \\
\hline 30 & Primary & $3+(\mathrm{c}-\mathrm{m})$ & $1+(\mathrm{m}-\mathrm{c})$ & $3+(\mathrm{m})$ \\
\hline 31 & Primary & $3+(\mathrm{c}-\mathrm{m})$ & $1+(\mathrm{n})$ & $3+(\mathrm{m})$ \\
\hline
\end{tabular}

m: membrane; c: cytoplasmic; n: nuclear; 0 : negative staining; $1+$ : $1-20 \%$ of positive cells; $2+$ : $21-50 \%$ of positive cells; $3+$ : more than $50 \%$ of positive cells; NE: not evaluable.
A high expression level of Notch-1 was consistently observed in adnexal structures, including hair follicle epithelium, sweat and sebaceous glands. In normal skin, a strong membranous staining for both $\beta$-catenin and E-cadherin was uniformly detected at the intercellular border of normal epithelial cells.

In Merkel cell carcinoma, all but one case showed moderate cytoplasmic and membrane expression of Notch-1 in more than $50 \%$ of tumor cells (Figure 1a and b). No statistically significant differences were observed in Notch expression and clinicopathological variables, including sex, location (extremities vs face vs trunk), primary vs metastatic Merkel cell carcinoma tumors as well clinical outcome.

All but 1 case (30 of 31) showed strong membranous staining for $\beta$-catenin (Figure 1c). Of these, 22 of $30(73.3 \%)$ showed membranous $\beta$-catenin expression in more than $50 \%$ of cells. Nuclear staining was seen in two cases, in combination with membranous staining. No statistically significant differences were observed in $\beta$-catenin expression and clinicopathological variables, including sex, location (extremities vs face vs trunk) as well as clinical outcome. Some of the cases undergoing disease progression showed downmodulation of Notch-1 immunohistochemical expression in comparison with nonprogressed cases, but the difference did not reach statistical significance.

E-cadherin expression was evaluated in 26 of 31 cases. Among 26 cases, 10 (38.5\%) were E-cadherin negative (Figure 1d). Fifteen cases (57.7\%) showed a markedly reduced membranous staining (expression in less than $20 \%$ of tumor cells). Only one case resulted in E-cadherin membrane-associated, linear pattern of expression that decorated the entire cell membrane in $80 \%$ of cells. Nuclear E-cadherin staining was observed in 3 of 26 cases, of which in 2 cases only nuclear positivity and in 1 case both nuclear and membranous positivities were detected. E-cadherin cytoplasmic staining, alone or in combination, was appreciated in 7 of 26 cases. No statistically significant differences were observed in E-cadherin expression and clinicopathological features, including clinical outcome.

Cutaneous metastases from lung carcinoids were Notch-1 negative whereas showed strong membranous expression of both $\beta$-catenin and E-cadherin (Figure 2a-d). Similarly, cutaneous metastasis from lung neuroendocrine carcinoma was weakly stained for Notch-1 in rare cells and showed strong membranous expression of both $\beta$-catenin and E-cadherin (Figure 3a-d). Finally, cutaneous melanoma with neuroendocrine differentiation showed a differential expression of Notch-1 in areas with neuroendocrine phenotype in comparison with nonneuroendocrine areas. In particular, in the neuroendocrine areas we observed a weaker Notch-1 signal in comparison with the strong cytoplasmic and membranous Notch-1 staining observed in nonneuroendocrine areas whereas strong membranous 

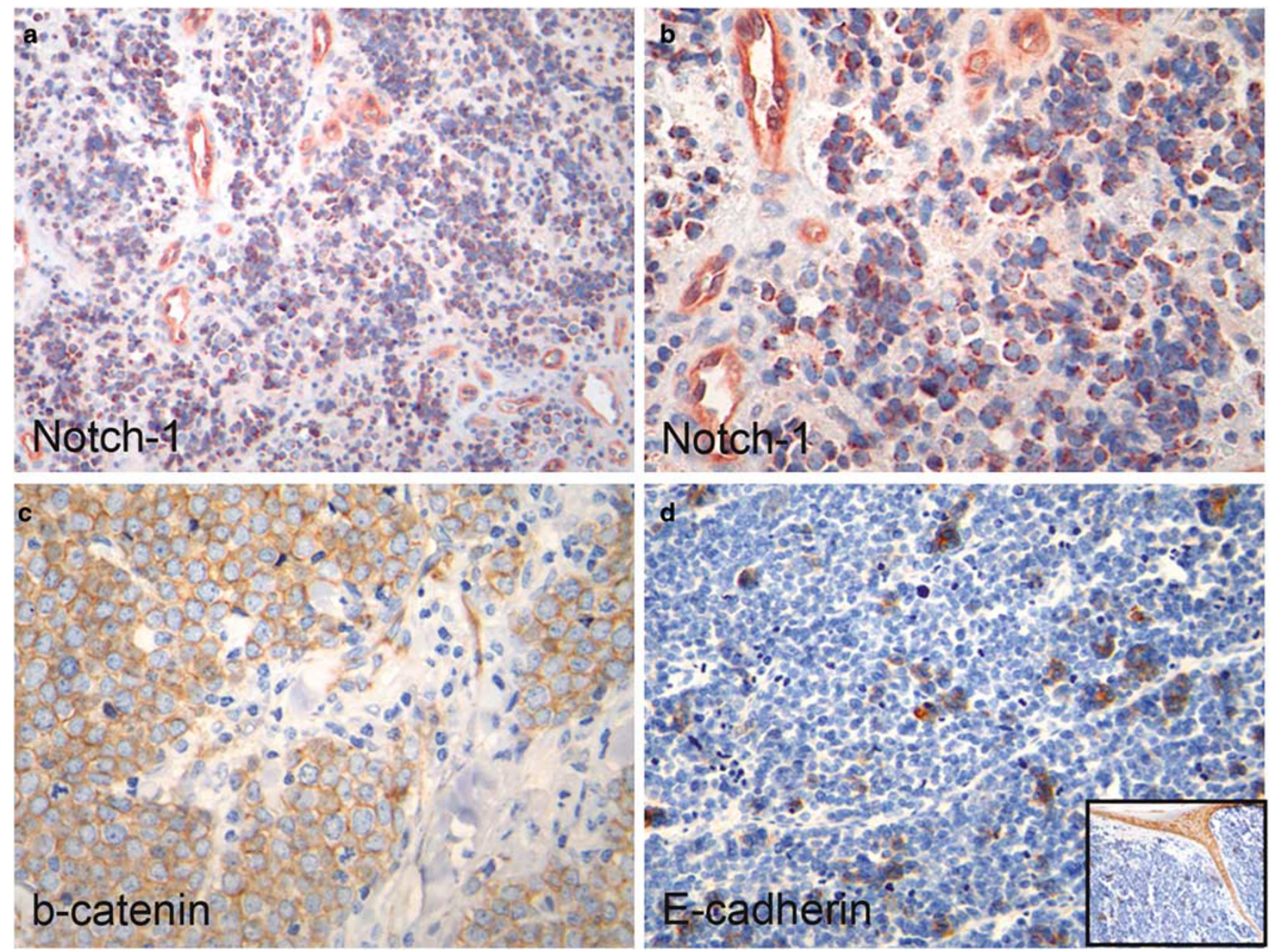

Figure 1 Merkel cell carcinoma: (a) Notch-1 cytoplasmic and membranous staining in Merkel cell carcinoma tumor cells (original magnification $\times 10$ ); (b) Notch-1 is also strongly expressed in endothelial cells of capillary vessels in the context of the tumor (original magnification $\times 40$ ); (c) strong membranous staining for $\beta$-catenin (original magnification $\times 40$ ); (d) E-cadherin positivity is observed at the membrane level only in rare scattered cells (original magnification $\times 20$ ); inset shows that the overlying epidermis is strongly E-cadherin positive with a membranous pattern (internal positive control) (original magnification $\times 10$ ).

$\beta$-catenin and E-cadherin staining was seen throughout the lesion (Figure $4 \mathrm{a}-\mathrm{d}$ ).

\section{Discussion}

The present study reports for the first time immunohistochemical expression of Notch-1 in Merkel cell carcinoma. In contrast to neuroendocrine tumors of other sites, ${ }^{8}$ detectable Notch- 1 was found in the majority of tumor cells, with moderate staining intensity. At present, the function of Notch1 in the control of cell proliferation of neuroendocrine Merkel cell carcinoma cells is unknown. If no firm conclusion can be drawn on this issue, the presence of Notch-1 in Merkel cell carcinoma does not argue for a suppressor function of this signaling pathway in Merkel cell carcinoma as it has been proposed for other neuroendocrine tumors. Notch-1 may also be implicated in the negative regulation of neuroendocrine phenotypic features in Merkel cell carcinoma and in the alterations of these processes that occur during tumor progression. Indeed, cancers with neuroendocrine features such as Merkel cell carcinoma frequently lose their characteristic endocrine phenotype in the course of tumor progression and it cannot be excluded that these tumors may be susceptible to negative regulation of neuroendocrine differentiation by Notch activation.

In the complex regulation of neuroendocrine phenotypic expression, there is increasing evidence for involvement of bHLH transcriptional enhancer factors and the Notch signaling. The Notch signaling has been shown to have a crucial inhibitory function in neuroendocrine differentiation in the lung and gastrointestinal tract ${ }^{15-17}$ through modulation of transcription factors. Human achaete-scute homologue 1 (hASH-1) is an evolutionarily conserved bHLH transcription factor that has a crucial function in the differentiation of endodermal endocrine cells. ${ }^{15,18}$ hASH-1 is suppressed by upregulation of HES-1 subsequent to Notch activation. ${ }^{1}$ Mouse 

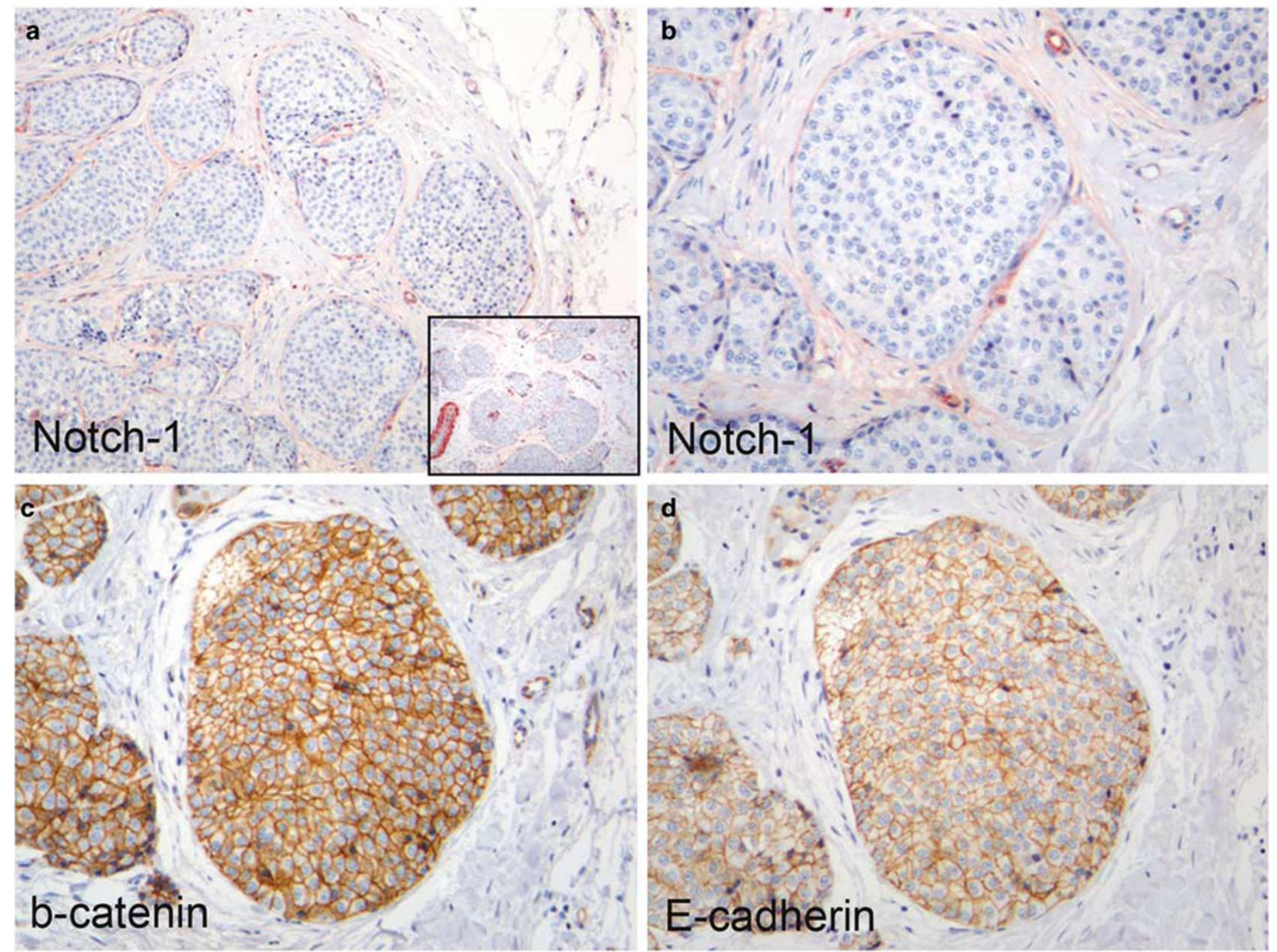

Figure 2 Skin metastasis from lung carcinoid: (a) Notch-1 is not expressed in the monomorphous epithelioid cells arranged in insulae with an organoid and trabecular pattern in the dermis (original magnification $\times 10$ ); inset shows strong Notch-1 expression with a medium-sized vessel in the context of the tumor (internal positive control) (original magnification $\times 10$ ); (b) Notch-1 is expressed in small capillary vessels whereas tumor cells are negative (original magnification $\times 20$ ); (c) $\beta$-catenin diffuse membranous staining in tumor cells (original magnification $\times 20$ ); (d) strong E-cadherin membranous staining in the majority of tumor cells (original magnification $\times 20)$.

atonal homologue 1 (MATH1) is another bHLH transcription factor that has an important function in Merkel cell maturation and maintenance of neuroendocrine phenotype. ${ }^{19,20}$ Activation of Notch by Jagged 2 inhibits expression of MATH1 in cochlear progenitor cells, possibly through HES- $5^{21}$ and MATH1 controls cerebellar granule cell differentiation as well as its own expression by regulating multiple components of the Notch pathway. ${ }^{22}$

Interestingly, $h A S H-1$ gene is expressed in neuroendocrine tumors including pheochromocytomas, medullary thyroid cancer, lung and thymic carcinoids and small-cell lung cancer $^{23,24}$ whereas RT-PCR analyses failed to demonstrate hASH-1 transcripts in any Merkel cell carcinoma cell line investigated, indicating that the neuroendocrine phenotype in Merkel cell carcinoma is not mainly related to hASH-1.20,25 Conversely, MATH1 is expressed in the classical Merkel cell carcinoma cell lines that are reactive for chromogranin A, indicating that MATH1 may be required for the maintenance of the neuroendocrine phenotype of Merkel cell carcinoma. ${ }^{20}$

In our study, analysis of skin metastases derived from neuroendocrine tumors revealed that, in contrast to the Notch-1 positivity in the vast majority of Merkel cell carcinoma, metastases from lung carcinoids and lung neuroendocrine carcinoma were essentially Notch-1 negative or weakly stained in a minority of cells. Thus, this study may add Notch-1 to the armamentarium of diagnostic reagents for neuroendocrine tumors involving the skin. In case of doubtful cases, lack or weak Notch-1 staining speaks against a diagnosis of Merkel cell carcinoma and the possibility of a metastatic neuroendocrine tumor should be taken into consideration. Variations of Notch-1 staining intensity in cutaneous neuroendocrine tumors may be related to both biological behavior and neuroendocrine differentiation, but further studies are necessary to clarify these issues. 

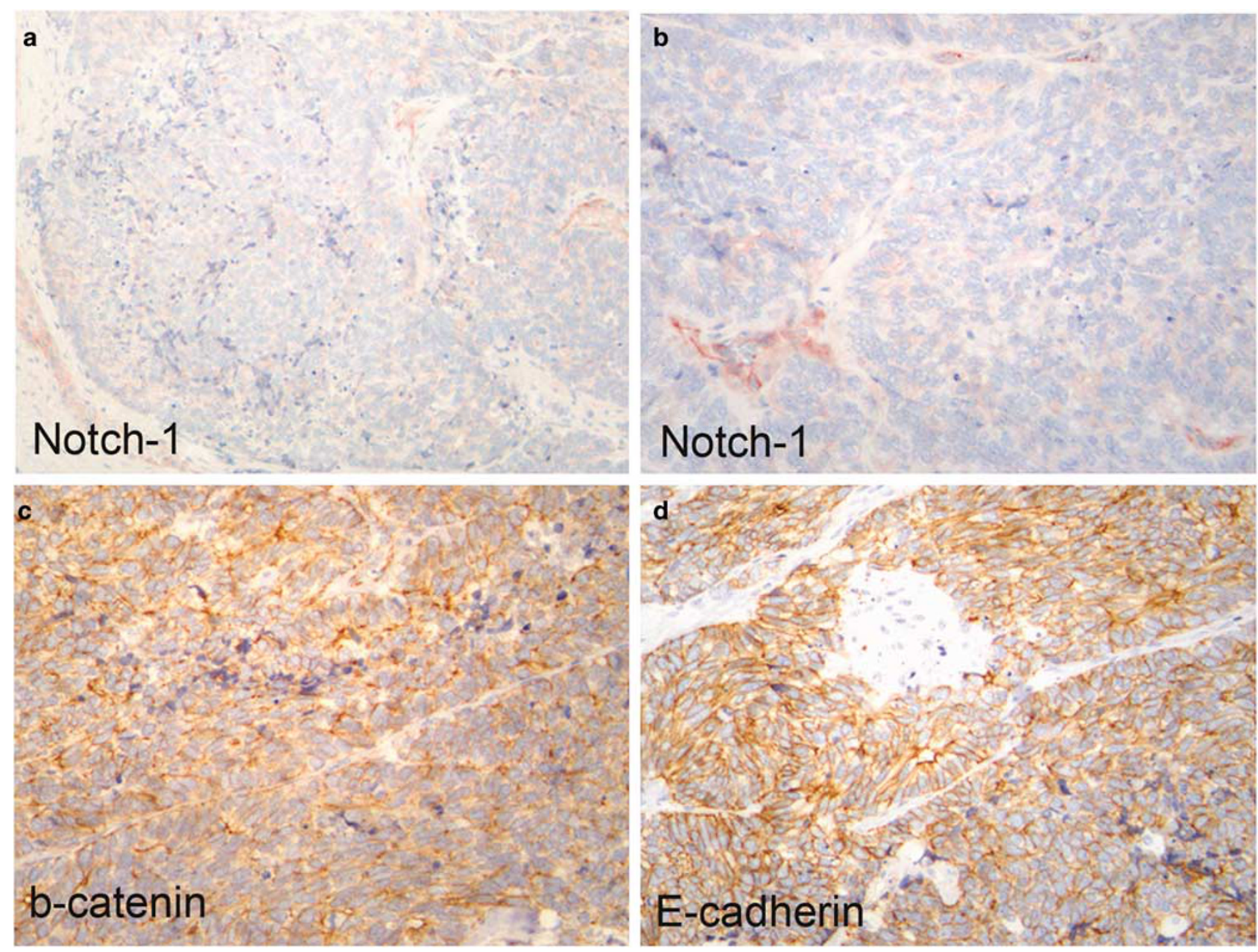

Figure 3 Skin metastasis from small-cell lung carcinoma: (a) weak Notch-1 expression is seen only in a minority of tumor cells (original magnification $\times 10$ ); (b) Notch-1 is strongly expressed in endothelial cells in the context of mostly unstained tumor cells (original magnification $\times 20$ ); $(\mathbf{c}) \beta$-catenin shows strong and diffuse membranous staining (original magnification $\times 20$ ); $(\mathbf{d})$ E-cadherin membranous staining in the majority of tumor cells (original magnification $\times 20$ ).

Worth mentioning is the rare case of cutaneous melanoma with neuroendocrine differentiation. Decreased Notch-1 staining was observed in areas with neuroendocrine features, which may further support a function of Notch in neuroendocrine differentiation. We have previously investigated the Notch pathway in a series of benign and malignant cutaneous melanocytic lesions and demonstrated that Notch activation represents an early event in melanocytic tumor growth and upregulation of Notch signaling may sustain tumor progression in melanoma. ${ }^{26}$ In contrast, we recently reported in nonmelanoma skin cancer a divergent expression of Notch-1, depending on anatomical site and tumor histotype. ${ }^{27}$ Whereas in UV-related squamous cell photocarcinogenesis Notch-1 downregulation occurred, mirroring a tumor-suppressor function of the receptor, in sun-protected squamous cell carcinomas Notch-1 was upregulated. ${ }^{27}$ Furthermore, Notch-1 expression was minimal in basal cell carcinoma subtypes, correlated with risk of recurrence (sclerodermiform/infiltrating and baso- squamous), in comparison with nodular and superficial types. ${ }^{27}$

Disruption of intercellular adhesion by alterations of cell adhesion molecules is one key step in invasive growth. ${ }^{28}$ Dysregulation of the E-cadherin/ $\beta$-catenin-dependent adhesion complex has been associated with the development and progression of several solid tumors, ${ }^{29}$ including neuroendocrine tumors. ${ }^{30-32}$ In our study, the vast majority of Merkel cell carcinoma showed a markedly reduced membranous E-cadherin staining and nuclear expression was observed in only 3 of 26 cases. Our results are fully in agreement with a previous study that reported a reduced membranous expression of E-cadherin in 22 of $23(95.7 \%)$ and nuclear E-cadherin in 4 of 23 cases of Merkel cell carcinoma. ${ }^{33}$ Reduced E-cadherin expression was correlated with tumor size and location outside the head and neck region, which are considered poor prognostic factors, thus supporting a function of E-cadherin dysregulation in mediating tumor progression. ${ }^{33}$ Absence of correlation between immunohistochemical parameters 

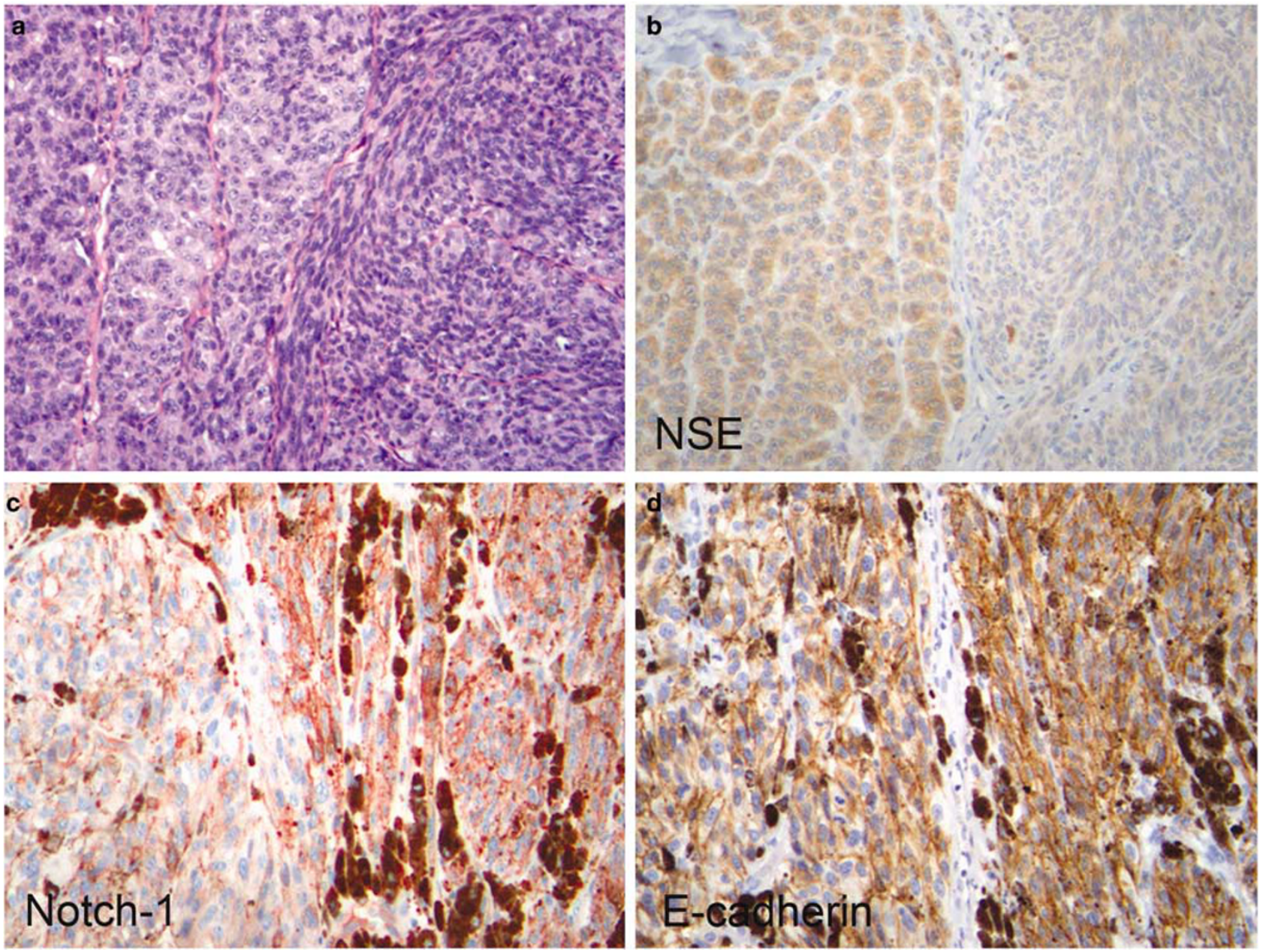

Figure 4 Cutaneous melanoma with area of neuroendocrine differentiation: (a) within a vertical growth phase cutaneous melanoma there is an area of neuroendocrine differentiation with trabecular pattern (left), (hematoxylin and eosin stain, original magnification $\times 20$ ); (b) in such area, neuronal-specific enolase (NSE) immunostaining is seen, thus confirming neuroendocrine differentiation (original magnification $\times 20)$; $(\mathbf{c})$ in the neuroendocrine area there is a weaker Notch-1 signal in comparison with the strong cytoplasmic and membranous Notch-1 staining observed in non-neuroendocrine areas (original magnification $\times 20$ ); (d) strong and diffuse E-cadherin membranous expression is seen in both neuroendocrine and non-neuroendocrine areas (original magnification $\times 20$ ).

with clinical outcome in our study may be the consequence of the relatively limited number of cases evaluated. A previous investigation reported E-cadherin staining in 34 of 35 Merkel cell carcinoma $(97 \%)$ with 18 cases with both membranous and nuclear staining, 2 cases only membranous staining and 14 only nuclear staining. ${ }^{34}$ The reasons for the difference between this and our study may be related to diverse cutoffs and antibodies as well as difficulties in the correct identification of crushing artifacts, which are common features of Merkel cell carcinoma.

In our study, membranous $\beta$-catenin expression was seen in 30 of 31 cases $(96.8 \%)$ whereas only in 2 cases $(6.5 \%)$ nuclear staining was detected. Consistent with our data, nuclear $\beta$-catenin was recently found only in 1 of $12(8.3 \%)$ Merkel cell carcinoma and membranous staining in all the cases $^{35}$ and, again, other studies reported nuclear $\beta$-catenin in $6^{34}$ and $3.2 \%^{33}$ of Merkel cell carcinoma. However, another study reported that 14 of 31 Merkel cell carcinoma showed decreased membranous $\beta$-catenin expression, 9 showed slightly reduced expression and 5 of 31 were negative. ${ }^{33}$ Apart from regulating cell adhesion and motility by binding to E-cadherin at the membrane level, $\beta$-catenin is the major nuclear transducer of the Wnt signaling pathway, which contributes to a wide variety of neoplasms. ${ }^{36}$ Wnt activation leads to stabilization and translocation of $\beta$-catenin from cytosol to nucleus, where it activates Wnt target genes such as $C$-myc and cyclin $D 1 .^{37,38}$ The significance of the subcellular localization of $\beta$-catenin (lack of nuclear staining in presence of membranous positivity) in Merkel cell carcinoma remains unclear. Loss of nuclear staining may suggest that Wnt pathway is not implicated in Merkel cell carcinoma pathogenesis, as previously proposed by others ${ }^{35}$ or, alternatively, Wnt pathway may be activated by different mechanisms. 
This is the first demonstration of Notch-1 expression in Merkel cell carcinoma. Notch-1 expression may exert biological functions both in undifferentiated (neuroendocrine) neoplastic cells or in Merkel cell carcinoma tumorigenesis, and further studies may address this important hypothesis. Presence of Notch-1 in Merkel cell carcinoma and lack in metastatic carcinoids suggests that Notch-1 may be of some diagnostic value in doubtful diagnoses of neuroendocrine skin cancer phenotype, and if these preliminary data would be confirmed by further studies, Notch-1 could be added to the armamentarium of diagnostic reagents for cutaneous neuroendocrine tumors. We also found that in Merkel cell carcinoma E-cadherin is downregulated whereas membranous $\beta$-catenin is diffusely expressed, indicating dysregulation of the E-cadherin/ $\beta$-catenin complex, which may contribute to local invasion and distant metastasis.

\section{Acknowledgement}

This study was financially supported by Fondazione Ente Cassa di Risparmio di Firenze.

\section{References}

1 Artavanis-Tsakonas S, Rand MD, Lake RJ. Notch signalling: cell fate control and signal integration in development. Science 1999;284:770-776.

2 Lai EC. Notch signaling: control of cell communication and cell fate. Development 2004;131:965-973.

3 Levitan D, Lee J, Song L, et al. PS1 N- and C-terminal fragments form a complex that functions in APP processing and Notch signalling. Proc Natl Acad Sci USA 2001;98:12186-12190.

4 Miele L, Golde T, Osborne B. Notch signalling in cancer. Curr Mol Med 2006;6:905-918.

5 Nakakura EK, Sriuranpong VR, Kunnimalaiyaan M, et al. Regulation of neuroendocrine differentiation in gastrointestinal carcinoid tumor cells by Notch signalling. J Clin Endocrinol Metab 2005;90:4350-4356.

6 Kunnimalaiyaan M, Vaccaro AM, Ndiaye MA, et al. Overexpression of the Notch1 intracellular domain inhibits cell proliferation and alters the neuroendocrine phenotype of medullary thyroid cancer cells. J Biol Chem 2006;281:39819-39830.

7 Sriuranpong V, Borges MW, Ravi RK, et al. Notch signalling induces cell cycle arrest in small cell lung cancer cells. Cancer Res 2001;61:3200-3205.

8 Kunnimalaiyaan M, Chen H. Tumor suppressor role of Notch-1 signaling in neuroendocrine tumors. Oncologist 2007;12:535-542.

9 Kohler S, Kerl H. Merkel cell carcinoma In: LeBoit PE, Burg G, Weedon D, Sarasin A (eds). World Health Organization classification of tumours. Pathology and Genetics of Skin Tumours. IARC Press: Lyon, 2006, pp 272-273.

10 Meeuwissen JA, Bourne RG, Kearsley JH. The importance of postoperative radiation therapy in the treatment of Merkel cell carcinoma. Int J Radiat Oncol Biol Phys 1995;31:325-331.
11 Skelton HG, Smith KJ, Hitchcock CL, et al. Merkel cell carcinoma: analysis of clinical, histologic, and immunohistologic features of 132 cases with relation to survival. J Am Acad Dermatol 1997;37: 734-739.

12 Nicolas M, Wolfer A, Raj K, et al. Notch 1 functions as a tumor suppressor in mouse skin. Nat Genet 2003;33:416-421.

13 Balint K, Xiao M, Pinnix CC, et al. Activation of Notch1 signaling is required for $\beta$-catenin-mediated human primary melanoma progression. J Clin Invest 2005;115:3166-3176.

14 Leong KG, Niessen K, Kulic I, et al. Jagged1-mediated Notch activation induces epithelial-to-mesenchymal transition through Slug-induced repression of E-cadherin. J Exp Med 2007;204:2935-2948.

15 Ito T, Udaka N, Yazawa T, et al. Basic helix-loophelix transcriptions factors regulate neuroendocrine differentiation on fetal mouse pulmonary epithelium. Development 2000;127:3913-3921.

16 Jensen J, Pedersen EE, Galante P, et al. Control of endodermal endocrine development by Hes-1. Nat Genet 2000;24:36-44.

17 Murtaugh LC, Stanger BZ, Kwan KM, et al. Notch signalling controls multiple steps of pancreatic differentiation. Proc Natl Acad Sci USA 2003;100: 14920-14925.

18 Borges M, Linnoila RI, van de Velde HJ, et al. An achaete-scute homologue essential for neuroendocrine differentiation in the lung. Nature 1997;386:852-855.

19 Ben-Arie N, Hassan BA, Bermingham NA, et al. Functional conservation of atonal and Math1 in the CNS and PNS. Development 2000;127:1039-1048.

20 Leonard JH, Cook AL, Van Gele M, et al. Proneural and proneuroendocrine transcription factor expression in cutaneous mechanoreceptor (Merkel) cells and Merkel cell carcinoma. Int J Cancer 2002;101: 103-110.

21 Landford PJ, Shailman R, Norton CR, et al. Expression of Math1 and HES5 in the cochleae of wildtype and Jag2 mutant mice. J Assoc Res Otolaryngol 2000;1: 161-171.

22 Gazit R, Krizhanovscy V, Ben-Arie N. Math1 controls cerebellar granule differentiation by regulating multiple components of the Notch signalling pathway. Development 2003;131:903-913.

23 Ball DW, Azzoli CG, Baylin SB, et al. Identification of a human achaete-scute homolog highly expressed in neuroendocrine tumors. Proc Natl Acad Sci USA 1993; 90:5648-5652.

24 Chen H, Udelsman R, Zeiger MA, et al. Human achaetescute homolog-1 is highly expressed in a subset of neuroendocrine tumors. Oncol Rep 1997;4:775-778.

25 Van Gele M, Boyle GM, Cook AL, et al. Geneexpression profiling reveals distinct expression patterns for classic vs variant Merkel cell phenotypes and new classifier genes to distinguish Merkel cell from small-cell lung carcinoma. Oncogene 2004;23: 2732-2742.

26 Massi D, Tarantini F, Franchi A, et al. Evidence for differential expression of Notch receptors and their ligands in melanocytic nevi and cutaneous malignant melanoma. Mod Pathol 2006;19:246-254.

27 Panelos J, Tarantini F, Paglierani M, et al. Photoexposition discriminates Notch 1 expression in human cutaneous squamous cell carcinoma. Mod Pathol 2008;23: $316-325$. 
28 Berx G, Noller F, Van Roy F. Dysregulation of the E-cadherin/catenin complex by irreversible mutations in human carcinomas. Cell Adhes Commun 1998;6: 171-184.

29 Polakis P. Wnt signalling and cancer. Genes Dev 2000;14:1837-1851.

30 Clavel CE, Nollet F, Berx G, et al. Expression of the E-cadherin-catenin complex in lung neuroendocrine tumours. J Pathol 2001;194:20-26.

$31 \mathrm{Li} \mathrm{CC}, \mathrm{Xu} \mathrm{B}$, Hirokawa $\mathrm{M}$, et al. Alterations of E-cadherin, $\alpha$-catenin and $\beta$-catenin expression in neuroendocrine tumors of the gastrointestinal tract. Virchows Arch 2002;440:145-154.

32 Pelosi G, Scarpa A, Puppa G, et al. Alteration of the E-cadherin/ $\beta$-catenin cell adhesion system is common in pulmonary neuroendocrine tumors and is an independent predictor of lymph node metastasis in atypical carcinoids. Cancer 2005;103:1154-1164.
33 Tanaka Y, Toshiaki S, Qian ZR, et al. Expression of adhesion molecules and cytokeratin 20 in Merkel cell carcinomas. Endocr Pathol 2004;15:117-130.

34 Han AC, Soler AP, Tang CK, et al. Nuclear localization of E-cadherin expression in Merkel cell carcinoma. Arch Pathol Lab Med 2000;124:1147-1151.

35 Liu S, Daa T, Kashima K, et al. The Wnt-signaling pathway is not implicated in tumorigenesis of Merkel cell carcinoma. J Cutan Pathol 2007;34:22-26.

36 Kikuchi A. Tumor formation by genetic mutations in the components of the Wnt signaling pathway. Cancer Sci 2003;94:225-229.

37 He TC, Sparks AD, Rago C, et al. Identification of c-MYC as a target of the APC pathway. Science 1998;281:1509-1512.

38 Tetsu O, McCoormick F. $\beta$-catenin regulates expression of cyclin D1 in colon carcinoma cells. Nature 1999;398:422-426. 